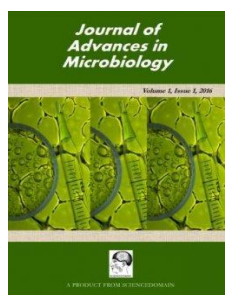

\title{
Induction and Expression of Chitinases from Four Sub Species of Bacillus thuringiensis
}

\author{
P. W. H. K. P. Daulagala ${ }^{1^{*}}$ \\ ${ }^{1}$ Department of Botany, Faculty of Natural Sciences, Kandy Regional Centre, The Open University of \\ Sri Lanka, Polgolla, Sri Lanka.
}

Author's contribution

The sole author designed, analyzed and interpreted and prepared the manuscript.

Article Information

DOI: $10.9734 / J A M B / 2017 / 34084$

Editor(s):

(1) Naim Deniz Ayaz, Department of Food Hygiene and Technology, Kirikkale University, Kirikkale, Turkey.

Reviewers:

(1) Eliton da Silva Vasconcelos, Federal University of São Carlos, Brazil.

(2) Essam Hussein Abdelshakour, Al-Azhar University, Cairo, Egypt.

Complete Peer review History: http://www.sciencedomain.org/review-history/19226

Original Research Article

Received $12^{\text {th }}$ May 2017

Accepted 24 ${ }^{\text {th }}$ May 2017

Published 29 $9^{\text {th }}$ May 2017

\begin{abstract}
Chitin is a naturally occurring linear polymer of $\mathrm{N}$-acetylglucosamine and the major structural component of fungal cell walls and exoskeletons of insects and arthropods. Chitinases are the enzymes that breakdown chitin to economically important derivatives and found in a range of organisms including bacteria, insects, crustaceans, invertebrates, some vertebrates and higher plants. In the present study, four Bacillus thuringiensis $(B t)$ isolates were grown in media supplemented with $0.1 \%(\mathrm{w} / \mathrm{v})$ regenerated chitin and chitinase inducing medium and screened for chitinolytic activity. All isolates showed notable extracellular chitinase activity with very low levels in cell bound fractions. When the isolates were screened with fluorogenic substrates, Bt HD133, Bt T7002 and Bt IPS78 showed a similar pattern of distribution with the highest production from Bt IPS 78. The lowest activity was detected from the isolate $B t 36-3$. Similar to the results obtained with fluorogenic substrates, Bt 36-3 and Bt IPS 78 expressed the lowest and the highest activities with the substrate Carboxymethyl-Chitin Remazol Brilliant Violet 5R (CM-chitin RBV 5R) respectively. When the culture supernatants of isolates grown in nutrient broth supplemented with regenerated chitin were electrophoresed on activity gels, one chitinase band of approximate molecular mass of $36 \mathrm{kDa}$ was obtained from all four sub species. Future experiments can be carried out to find out whether these chitinases have any insecticidal activity aiming, to develop environmental-friendly biopesticides, and in vivo antifungal activities to test against plant pathogenic fungi in growth chambers and under glasshouse condition.
\end{abstract}


Keywords: Bacillus thuringiensis; chitinase; 4-methylumbelliferyl substrates; Carboxymethyl-Chitin Remazol Brilliant Violet 5R; chitinase inducing medium.

\section{INTRODUCTION}

Chitin is a long unbranched polymer of an amino sugar $N$-acetyl- $\beta$-D-glucosamine residues (GlcNAc) linked together by $\beta-1,4-g l y c o s i d i c$ linkages [1]. This naturally occurring polymer is the second most frequent biopolymer in the environment after cellulose and present in insects, crustaceans and most fungi, but not in plants, vertebrates and prokaryotes. Chitin is hydrolyzed by two types of enzymes, namely chitinase (E.C. 3.2.1.14) and N-acetyl glucosaminidase (E.C. 3.2.1.52).

According to the nomenclature suggested by [2], the chitinolytic enzymes are divided into three principal types: endochitinase, exochitinase and $\mathrm{N}$-acetylglucosaminidase. Endochitinases and exochitinases are the two major categories of chitinases. Chitinases catalyse the conversion of chitin to its monomeric components. They are produced by a large variety of chitin-degrading organisms including several bacteria $[3,4,5]$ actinomycetes [6,7], fungi [8] and also by higher plants $[9,10,11,12]$.

Bacillus thuringiensis (Bt) is an insecticidal, Gram-positive rod-shaped, motile, spore forming bacterium widely used as a biocontrol agent against pests. Bt produces parasporal crystalline inclusion bodies containing highly specific insecticidal proteins called Cry proteins or $\delta$ endotoxins. These toxins are mainly active against lepidopteran species and some also shows toxicity against dipteran and coleopteran species and other organisms [13]. Under suitable conditions, $B t$ is capable of producing many biological active molecules, for examples bacteriocins and hydrolytic enzymes such as chitinases. Chitinases of $B$. thuringiensis are worth of consideration due to their potential role as biological control agents for insects and plant-pathogenic fungi $[14,15]$.

In this present study, chitinases produced by four subsp. of Bacillus thuringiensis were assayed using 4-methylumbelliferyl fluorogenic substrates and a dye substrate and their antifungal activity was investigated against Botrytis cinerea, the causative organism of grey mold disease.

\section{MATERIALS AND METHODS}

\subsection{Bacterial Isolates and Culture Conditions}

Bacillus thuringiensis subsp. israelensis IPS 78 and subsp. aizawai HD 133 were kindly provided by the University of Cambridge, United Kingdom. $B$. thuringiensis subsp. aizawai T7002 and subsp. israelensis 36-3 (isolated in Brazil) were obtained from the Heriot-Watt University, Edinburgh, Scotland. All bacteria were grown in liquid media; nutrient broth (NB) without regenerated chitin, nutrient broth supplemented with $0.1 \%(\mathrm{w} / \mathrm{v})$ regenerated chitin and Chitinase inducing medium (CIM) [16].

\subsection{Preparation of Bacterial Cultures for Chitinases Assay}

Cultures were incubated with shaking (Varishaker-Incubator, Dynatech) for 96 hours. Following incubation, cultures were centrifuged at $11,600 \mathrm{~g}$ for $15 \mathrm{~min}$. The supernatant and the pellet of each culture were collected separately to individual sterile containers and stored at $20^{\circ} \mathrm{C}$ until required.

\subsection{Synthesis of Glycol Chitin}

Glycol chitosan (Sigma, UK) was prepared according to the method of [17], an adaptation of the method by [18]. The final concentration of the stock suspension of glycol chitin was made as a $1 \%(\mathrm{w} / \mathrm{v})$ and stored at $4^{\circ} \mathrm{C}$ until use.

\subsection{Preparation of Regenerated Chitin}

Regenerated chitin was prepared according to the method by [18] using chitosan (Sigma, UK). The concentration of prepared chitin was determined by lyophilisation and weighing of a small sample. The suspension was stored at $4^{\circ} \mathrm{C}$ until use.

\subsection{Assay for Chitinases with 4- methylumbelliferyl Fluorogenic Sub- strates}

The fluorometric assay developed by [19] was used. In this assay, four 4-methylumbelliferyl fluorogenic substrates 4- $\mathrm{MU}-(\mathrm{GlcNac})_{1-4}$ (S1S4) were used. Working solutions of monomer 
[4-MU-(GIcNAc) $)_{1}$ ], dimer [4-MU-(GlcNAc $)_{2}$ ] and trimer [4-MU-(GlcNAc) $)_{3}$ ] (Sigma Chemical Co.) were prepared at a concentration of $0.8 \mathrm{mM}$ in sterile distilled water. The tetramer [4-MU(GlcNAc) $)_{4}$ (Janssen Biochemica) was prepared at the same concentration in $50 \%(\mathrm{v} / \mathrm{v})$ ethanol. All substrate solutions were kept at $-20^{\circ} \mathrm{C}$. The use of these substrates allows discrimination between $\beta-N$-acetylglucosaminidase [hydrolysing 4-MU-GIcNAc) $)_{1}$, exochitinase [hydrolysing 4-MU-(GlcNAc $)_{2}$ ] and endochitinase [hydrolysing 4-MU-(GlcNAc $)_{3}$ and 4-MU$\left.(\mathrm{GlcNAc})_{4}\right]$ [19].

The reaction mixture in each well contained $20 \mu \mathrm{l}$ enzyme preparation, $80 \mu \mathrm{l}$ Mcllvaine's buffer $(0.1$ $\mathrm{M}$ citric acid and $0.2 \mathrm{M}$ dibasic sodium phosphate, $\mathrm{pH}=6$ ) and $5 \mu \mathrm{l}$ of each $0.8 \mathrm{mM} 4-$ MU substrate. First, the enzyme extract was incubated with the buffer at $37^{\circ} \mathrm{C}$ for $5 \mathrm{~min}$ in a shaking incubator (Varishaker-Incubator, Dynatech). Then the substrates were added to the wells and the plates were incubated at $37^{\circ} \mathrm{C}$ for $60 \mathrm{~min}$. After incubation, the plates were read with the Fluoroskan II fluorometer (Titertek Instruments). Then $120 \mu$ of stop buffer (1 M $\mathrm{NaOH} /$ glycine $\mathrm{pH}$ 10.6) was added to each well and the plates were read again to get the endpoint fluorescence after 5 min incubation with stop buffer at $37^{\circ} \mathrm{C}$. Control wells contained the reaction mixture without the substrates and the reaction mixture with boiled enzyme extract. The control wells without substrate contained $5 \mu \mathrm{l}$ more buffer to keep the final volume constant. In calculating the activity, the mean fluorescence of control wells was subtracted from the test samples. All assays were performed in triplicate. Enzyme activity was expressed as katal. One katal is the amount of enzyme catalysing the conversion of one mole of substrate to product, in one second.

\subsection{Assay for Chitinases with Carboxymethyl-chitin Remazol Brilliant Violet 5R}

Assay for Chitinases with Carboxymethyl-Chitin Remazol Brilliant Violet 5R (CM-chitin-RBV 5R) was carried out as described by [20]. Reaction mixtures contained the enzyme preparation, $0.1 \mathrm{M}$ sodium citrate buffer $(\mathrm{pH}=5)$ and CM-chitin-RBV $5 \mathrm{R}$ solution. The enzyme activity was expressed as the change in absorbance at $550 \mathrm{~nm} \mathrm{~h}{ }^{-1}$. The assays were carried out in triplicates for each sample and the activity was expressed as a mean of these three replicates.

\subsection{Chitinase Isozyme Patterns in SDS- PAGE Activity Gels}

SDS-PAGE was carried out as described by [17] using glycol chitin impregnated separating gels, with the buffer system of [21]. For activity gels, $12 \%$ separating gels containing $0.1 \%(\mathrm{w} / \mathrm{v})$ glycol chitin and $4 \%$ stacking gels were used. Lytic zones in gels, where chitin had been digested, were detected by inspection of gels in a UV illuminator, where they appeared as dark bands against the fluorescent background of intact glycol chitin [17].

\subsection{Screening of $B$. thuringiensis for Antagonism in vitro against Botrytis cinerea}

All four subsp. of $B$. thuringiensis were screened against $B$. cinerea using a dual culture technique [22]. Further, supernatant fractions of bacterial cultures used for chitinase assays were also screened. Central wells $(10 \mathrm{~mm}$ diameter cork borer) were cut in PDA plates seeded with conidia of $B$. cinerea. The wells were filled to capacity $(200 \mu \mathrm{l})$ with filter-sterilised $(0.2 \mu \mathrm{m}$ Acrodisc) culture supernatants of $B t$ isolates grown in nutrient broth supplemented with regenerated chitin. Plates were incubated at $21^{\circ} \mathrm{C}$ and observed for zones of inhibition. Proteins in wells were concentrated by adding up to $200 \mu \mathrm{l}$ of appropriate culture supernatant daily at the first 3 days of incubation.

\section{RESULTS AND DISCUSSION}

Various species of Bacillus have been shown to secrete chitinases, including Bacillus amyloliquefaciens [23], Bacillus cereus [24], Bacillus circulans [25], Bacillus licheniformis [26], Bacillus megaterium [23], Bacillus subtilis [27], Bacillus thuringiensis sub sp. aizawai [15] and $B$. thuringiensis sub sp. kurstaki [14]. Production of chitinases by different strains of $B$. thuringiensis and the involvement of these chitinases during pathogenesis of insects has been demonstrated [16].

Most of the microbial chitinolytic systems are inducible [28], but the production of chitinolytic enzymes in bacteria has been reported to be both constitutive [29] and inducible [30,31]. Hence in this study, Bt isolates were grown in appropriate liquid media with and without the supplement of regenerated chitin in order to assay both constitutive and inducible chitinase activities. All four sub species of $B$. thuringiensis 
screened in this study produced chitinases when grown in liquid media containing chitin. But [32] have purified a $36 \mathrm{kDa}$ chitinase by ion exchange and gel filtration chromatography from the culture supernatant of Bacillus thuringiensis HD-1 and this chitinase production was independent of the presence of chitin in the growth medium and was produced even in the presence of glucose.

The fluorometric assay was used as the principal assay to determine the chitinolytic activities. Although this assay is highly sensitive and reliable, it is expensive. Four of the 4methylumbelliferyl fluorogenic substrates detect different enzymes in the chitinolytic system $(\mathrm{N}$-acetylglucosaminidase, exochitinase and endochitinase). Therefore the results can be used to get an idea about the overall chitinase production of each isolate as well as the level of production of individual enzyme in the chitinolytic system. Both extracellular (culture supernatant) and cell-bound (cellular) activities were detected, but the latter with very low levels. According to the results obtained, [30] suggested that the occurrence of chitinase activity in cellular fraction of highly chitinolytic bacteria could actually be due to an intracellular enzyme, but could also result from an incomplete release of the enzyme to the growth medium.

Negligible levels of chitinolytic activities were detected in both assays, upon growth of $B$. thuringiensis in nutrient broth in the absence of chitin (results not shown). This indicated that chitinases were induced in the presence of regenerated chitin in the growth medium. Significant levels of chitinolytic activities were detected in the supernatant fractions of all four $B$. thuringiensis sub species when grown in NB supplemented with $0.1 \%(\mathrm{w} / \mathrm{v})$ regenerated chitin and chitinases inducing medium (CIM) (Fig. 1) in contrast to the very low activities of cellular (cellbound) fractions (Table 1). Except for Bt 36-3, other three isolates showed higher chitinase activities with 4-methylumbelliferyl fluorogenic substrates when grown in NB supplemented with regenerated chitin. This result indicates that all isolates of $B$. thuringiensis showed notable extracellular exochitinase [hydrolysing 4-MU$(\mathrm{GlcNAc})_{2}$ ] and endochitinase [hydrolysing 4-MU$(\mathrm{GlcNAc})_{3}$ and 4-MU-(GICNAc) $)_{4}$ ] activities.

There were no detectable $\mathrm{N}$-acetylglucosaminidase activities in cell-bound or supernatant fractions when the cells were grown in NB medium either with or without regenerated chitin. In contrast, very low levels of $\mathrm{N}$ acetylglucosaminidase activities were detected only in culture supernatants of chitinase inducing medium (Fig. 1).

When four subsp. of $B$. thuringiensis were screened for chitinolytic enzymes with fluorogenic substrates, Bt HD133, Bt T7002 and Bt IPS78 showed a similar pattern of distribution (Fig. 1) with the highest production from $B t$ IPS78. For all isolates, the highest was the exochitinase activity with 4-MU-(GlcNAc $)_{2}$ and the lowest was the $\mathrm{N}$-acetylglucosaminidase activity with 4-MU-(GlcNAc) $)_{1}$. When [16]

Table 1. Chitinase activities (fkat $\mathrm{ml}^{-1}$ culture) of culture supernatant (S) and cell-bound (C) fractions of four subsp. of $B$. thuringiensis against 4-MU substrates. Mean activities of triplicate wells \pm SE are given

\begin{tabular}{llllllll}
\hline $\begin{array}{l}\text { Sub } \\
\text { species }\end{array}$ & S/C & \multicolumn{3}{c}{ NB + regenerated chitin } & \multicolumn{3}{c}{ CIM } \\
\cline { 2 - 7 } & & $\begin{array}{l}\text { 4-MU- } \\
(\text { GIcNAc) }\end{array}$ & $\begin{array}{l}\text { 4-MU- } \\
\text { (GIcNAc) }\end{array}$ & $\begin{array}{l}\text { 4-MU- } \\
\text { (GIcNAc) }\end{array}$ & $\begin{array}{l}\text { 4-MU- } \\
\text { (GIcNAc) }\end{array}$ & $\begin{array}{l}\text { 4-MU- } \\
\text { (GIcNAc) }\end{array}$ & $\begin{array}{l}\text { 4-MU- } \\
\text { (GIcNAc) }\end{array}$ \\
\hline Bt 36-3 & S & $650 \pm 90$ & $133 \pm 14$ & $358 \pm 28$ & $733 \pm 38$ & $50 \pm 0$ & $716 \pm 52$ \\
& C & $102 \pm 4$ & $28 \pm 0$ & $71 \pm 4$ & $118 \pm 5$ & $19 \pm 1$ & $69 \pm 1$ \\
Bt IPS78 & S & $1366 \pm 16$ & $142 \pm 8$ & $942 \pm 8$ & $1025 \pm 8$ & $100 \pm 8$ & $667 \pm 8$ \\
& C & $126 \pm 10$ & $26 \pm 0$ & $78 \pm 3$ & $123 \pm 4$ & $25 \pm 1$ & $97 \pm 7$ \\
Bt HD133 & S & $1208 \pm 8$ & $183 \pm 8$ & $875 \pm 0$ & $433 \pm 8$ & $108 \pm 0$ & $317 \pm 0$ \\
& C & $144 \pm 6$ & $29 \pm 3$ & $81 \pm 1$ & $110 \pm 7$ & $17 \pm 1$ & $35 \pm 3$ \\
Bt T7002 & S & $1267 \pm 8$ & $133 \pm 8$ & $892 \pm 12$ & $442 \pm 0$ & $75 \pm 0$ & $250 \pm 8$ \\
& C & $132 \pm 4$ & $32 \pm 2$ & $82 \pm 2$ & $102 \pm 1$ & $15 \pm 1$ & $33 \pm 2$ \\
\hline
\end{tabular}

Key: S: Supernatant, C: Cell-bound, NB: Nutrient broth, CIM: Chitinase inducing medium 

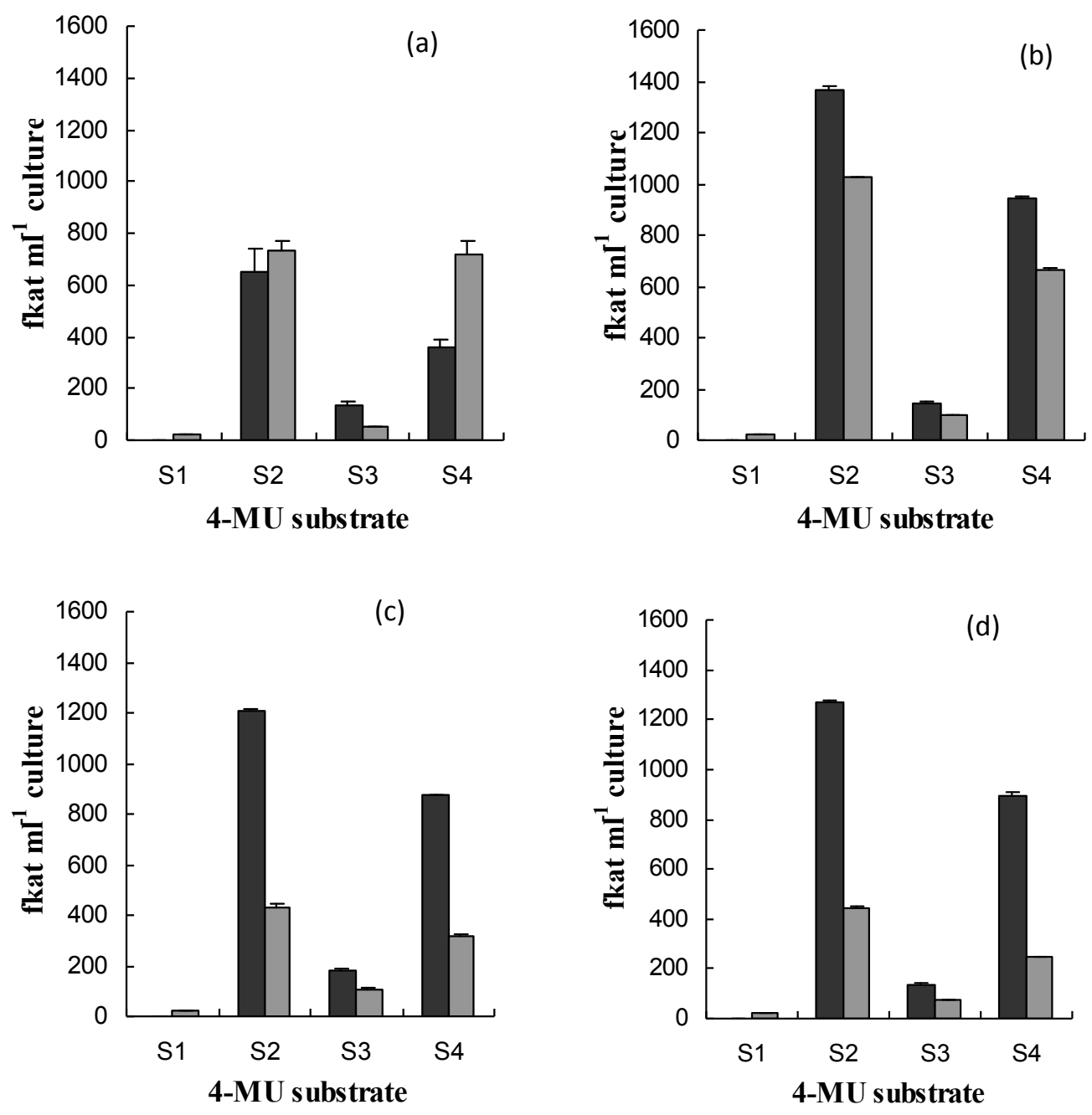

Fig. 1. Chitinolytic activities of supernatant fractions of $B$. thuringiensis

(a) B. thuringiensis 36-3, (b) B. thuringiensis IPS78, (c) B. thuringiensis HD133 and (d) B. thuringiensis T7002. Cells were grown in nutrient broth supplemented with $0.1 \%(w / v)$ regenerated chitin $(\square)$ and chitinase inducing medium ( $\square$ ). The mean activities of three replicate wells \pm SE are given

assayed several isolates of $B$. thuringiensis including Bt HD133 and Bt IPS78 in fluorometric assay, high activities were obtained with 4-MU$(\mathrm{GlcNAc})_{2}$ (exochitinase) followed by 4-MU$(\mathrm{GlcNAc})_{3}$ (endochitinase) and lower activities with 4-MU-(GlcNAc) 1 ( $N$-acetylglucosaminidase)

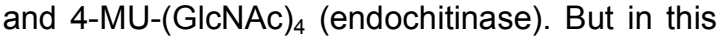
present study, higher endochitinase activity with 4-MU-(GIcNAc) $)_{4}$ was obtained for all four sub species than that of with 4-MU-(GlcNAc) ${ }_{3}$ (both these substrates detect the activity of endochitinase). This may be due to some different growth conditions applied in two studies such as the concentration of regenerated chitin in the growth medium.
The chitinase activities of the culture supernatants of $B$. thuringiensis against the substrate CM-chitin RBV are shown in Fig. 2. Chitinase activities of the supernatant fractions of four sub species of $B t$ detected in two assays used in this study showed a same pattern of distribution. Similar to the results obtained with 4-methylumbelliferyl fluorogenic substrates, $B t$ 36-3 and Bt IPS 78 expressed the lowest and the highest activities with the substrate $\mathrm{CM}$-chitin RBV respectively.

When the culture supernatants of four $B$. thuringiensis sub species grown in nutrient broth supplemented with regenerated chitin were 


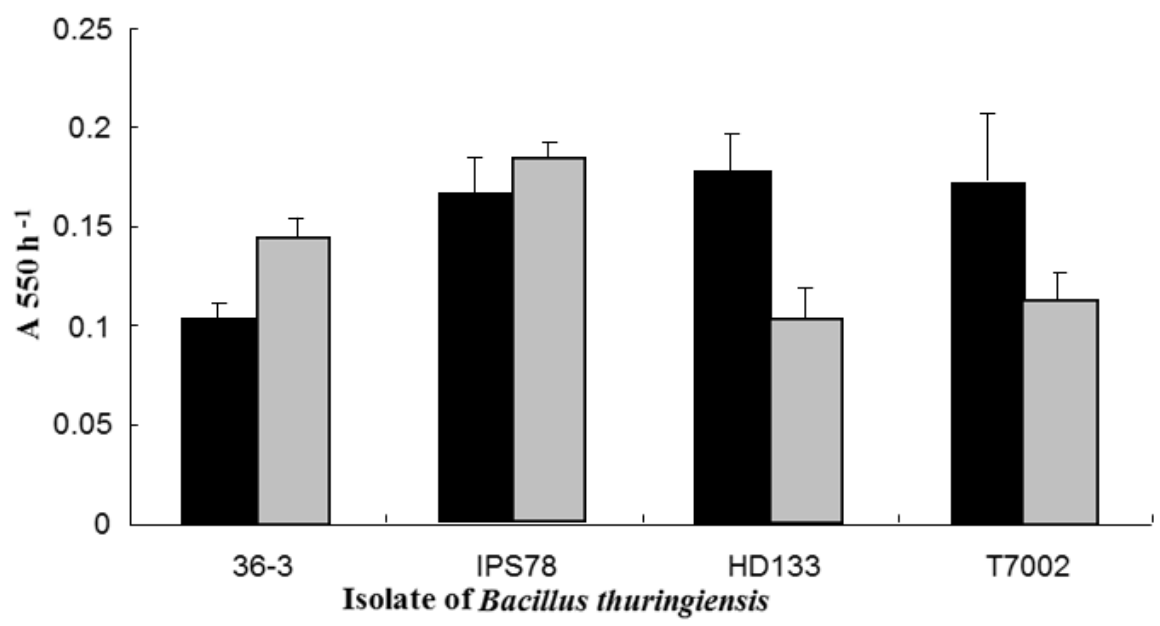

Fig. 2. Chitinase activities of the supernatant fractions of four subsp. of $B$. thuringiensis with CM-chitin RBV

Cells were grown in Nutrient broth supplemented with regenerated chitin ( $\mathbf{U}$ ) and Chitinase inducing medium

$(\square)$. The mean absorbances of triplicate assays \pm SE are given

electrophoresed on activity gels, one chitinase band of approximate molecular mass of $36 \mathrm{kDa}$ was obtained from all four sub species (Fig. 3). $B$. thuringiensis 36-3 which showed the lowest activity in assays gave a faint band in the activity gel. Hen egg white lysozyme (HEWL) and purified chitinase from Streptomyces griseus were used as positive controls.

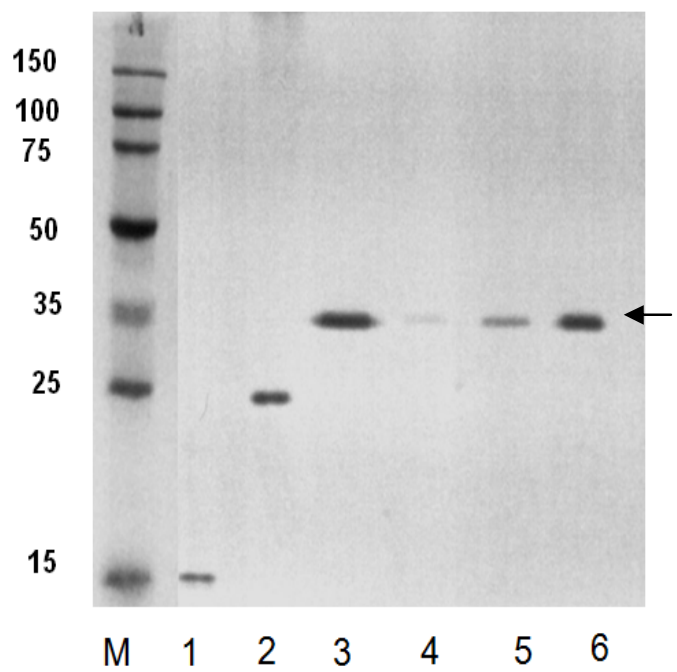

A chitinase of approximate molecular mass of 39 $\mathrm{kDa}$ (Chi39) had been detected by [33] from $B$. thuringiensis serovar konkukian S4 and purified Chi39 has shown antifungal activity against the phytopathogenic fungi such as Fusarium oxysporum and Aspergillus niger. A chitinase Chi255 from B. thuringiensis subsp. kurstaki showed in vitro antifungal activity against

1- hen egg white lysozyme (HEWL)

2- Streptomyces griseus chitinase

3- $B t$ IPS78

4- Bt 36-3

5- $\quad B t \mathrm{HD} 133$

6- Bt T7002

Fig. 3. Detection of chitinase activity of four subsp. of $B$. thuringiensis in SDS-PAGE activity gels containing glycol chitin. The supernatants of the cultures grown in nutrient broth supplemented with regenerated chitin were used. The standard molecular markers (Novagen perfect protein markers) are shown in the left. The position of $36 \mathrm{kDa}$ chitinase is indicated with an arrow 
A. niger that causes black blight of onion and peanut [14]. Further, when several $B t$ isolates were screened for the antifungal activity by [34], a complete inhibition of the growth of Fusarium oxysporum f. sp. cubense was noticed with $B t$ isolates $50 \mathrm{E}$ and $48 \mathrm{~F}$ and Beauveria bassiana with 50E, 48F, 47C, 24B, 13.2, Al2.3, 50B and 30 , whereas some of the $B t$ isolates were found to inhibit Sclerotium rolfsii to an extent of $75 \%$. Among these, some of them have also inhibited Aspergillus flavus to an extent of almost $50 \%$. In this present study, when the crude culture supernatants of four subsp. of $B t$ were screened against Botrytis, no growth inhibition was obtained in vitro. A possible explanation was given by [35] for the limitation of antifungal activity of many bacterial chitinases when tested in growth inhibition experiments. One reason may be that the bacterial exochitinases, digest chitin chains starting from the non-reducing end of the chain, which may be difficult in intact fungal cell walls. In contrast, most plant chitinases (endochitinases) can cleave any portion of the chitin polymer with which they come in contact. But in this study, this may be not the only reason and there could be some other factors such as the crude condition of the enzyme, concentration of enzyme extract applied in each well and the incubation conditions used for Botrytis (eg. $21^{\circ} \mathrm{C}$ ) might be not the optimum for the activity of chitinases.

\section{CONCLUSION}

In conclusion, the present work shows the chitinolytic activities of four subsp. of Bacillus thuringiensis under in vitro conditions. But more work is needed towards further characterization of chitinases in these isolates. Future experiments can be carried out to reveal whether these enzymes have any insecticidal activity and furthermore, to develop environmental-friendly biopesticides, in vivo antifungal activities of these chitinases can be examined against plant pathogenic fungi in growth chambers and under glasshouse condition.

\section{COMPETING INTERESTS}

Author has declared that no competing interests exist.

\section{REFERENCES}

1. Chuan DL. Review of fungal chitinases. Mycopathologia. 2006;161:345-60.

2. Sahai AS, Manocha MS. Chitinases of fungi and plants: Their involvement in morphogenesis and host-parasitic interaction. FEMS Microbiol Rev. 1993;11: 317-38.

3. Wen CM, Tseng CS, Cheng CY, Li YK. Purification, characterization and cloning of a chitinase from Bacillus sp. NCTU2. Biotechnol Appl Bioc. 2002;35:213-19.

4. Huang CJ, Wang TK, Chung SC, Chen $\mathrm{CY}$. Identification of an antifungal chitinase from a potential biocontrol agent, Bacillus cereus 28-9. J Biochem Mol Biol Sci. 2005;38:82-88.

5. Ajit NS, Verma R, Shanmugam V. Extracellular chitinases of fluorescent pseudomonads antifungal to Fusarium oxysporum f. sp. dianthi causing carnation wilt. Curr Microbiol. 2006;52:310-16.

6. El-Tarabily KA, Soliman $\mathrm{MH}$, Nassar $\mathrm{AH}$, Al-Hassani HA, Sivasithambaram K, McKenna F, Hardy GEST. Biological control of Sclerotinia minor using a chitinolytic bacterium and actinomycetes. Plant Pathol. 2000;49:573-83.

7. Akagi K, Watanabe J, Hara M, Kezuka Y, Chikaishi E, Yamaguchi T, Akutsu, H, Nonaka T, Watanabe T, Ikegami T. Identification of the substrate interaction region of the chitin-binding domain of Streptomyces griseus chitinase C. J Biochem (Tokyo). 2006;139:483-93.

8. Viterbo A, Haran S, Friesem D, Ramot $O$, Chet I. Antifungal activity of a novel endochitinase gene (chit36) from Trichoderma harzianum Rifai TM. FEMS Microbiol Lett. 2001;200:169-74.

9. Mauch F, Hadwiger LA, Boller T. Ethylene: Symptom, not signal for the induction of chitinase and beta-1,3glucanase in pea pods by pathogens and elicitors. Plant Physiol. 1984;76:607-11.

10. Collinge DB, Kragh KM, Mikkelsen JD, Nielsen KK, Rasmussen U, Vad K. Plant chitinases. Plant J. 1993;3:31-40.

11. Graham LS, Sticklen MB. Plant chitinases. Can J Bot. 1994;72:1057-83.

12. Daulagala PWHKP, Allan EJ. L-form bacteria of Pseudomonas syringae pv. phaseolicola induce chitinases and enhance resistance to Botrytis cinerea infection in Chinese cabbage. Physiol Mol Plant Pathol. 2003;62:253-63.

13. Martin PA, Gundersen DE, Blackburn MB. Distribution of phenotypes among Bacillus thuringiensis strains. Syst Appl Microbiol. 2010;33:204-208.

14. Driss F, Kallassy_Awad M, Zouari N, Jaoua S. Molecular characterization of a 
novel chitinase from Bacillus thuringiensis subsp. kurstaki. J Appl Microbiol. 2005;99: 945-53.

15. De la Vega LM, Barboza-Corona JE, Aguilar-Uscanga MG, Ramirez_lepe $M$. Purification and characterization of an exochitinase from Bacillus thuringiensis subsp. aizawai and its action against phytopathogenic fungi. Can $\mathrm{J}$ Microbiol. 2006;52:651-57.

16 Sampson MN. Role of chitinases in bacterial insect pathogens. Ph.D Thesis, University of Aberdeen; 1997.

17. Trudel J, Asselin A. Detection of chitinase activity after polyacrylamide gel electrophoresis. Anal. Biochem. 1989; 178(2):362-66.

18. Molano J, Duran AU, Cabib E. A rapid and sensitive assay for chitinase using tritiated chitin. Anal Biochem.1977;83:64856.

19. McCreath KJ, Gooday GW. A rapid and sensitive micro assay for determination of chitinolytic activity. J Microbiol Methods. 1992;14:229-37.

20. Wirth SJ, Wolf GA. Dye-labeled substrates for the assay and detection of chitinase and lysozyme activity. J Microbiol Methods. 1990;12:197-205.

21. Laemmli UK. Cleavage of structural proteins during the assembly of the head of bacteriophage. Nature. 1970;227:68085.

22. Whipps JM. Effect of media on growth and interactions between a range of soil borne glasshouse pathogens and antagonistic pathogens. New Phytol. 1987; 107:127 -142.

23. Sabry SA. Microbial degradation of shrimpshell waste. J Basic Microbiol. 1992;32(2): 107-11.

24. Chang WT, Chen YC, Jao CL. Antifungal activity and enhancement of plant growth by Bacillus cereus grown on shellfish chitin wastes. Bioresour Technol. 2007;98:1224230

25. Chen CY, Wang YH, Huang CJ. Enhancement of the antifungal activity of Bacillus subtilis $\mathrm{F} 29-3$ by the chitinase encoded by Bacillus circulans chiA gene. Can J Microbiol. 2004;50:451-54.

26. Waldeck J, Daum G, Bisping B, Meinhardt $\mathrm{F}$. Isolation and molecular characterization of chitinase deficient Bacillus licheniformis strains capable of deproteinization of shrimp shell waste to obtain highly viscous chitin. Appl Environ Microbiol. 2006; 72(12):7879-885.

27. Wang SL, Lin TY, Yen YH, Liao HF, Chen YJ. Bioconversion of shellfish chitin wastes for the production of Bacillus subtilis W118 chitinase. Carbohydr Res. 2006;341: 2507-515.

28. Monreal J, Reese ET. The chitinase of Serratia marcescens. Can J Microbiol. 1969;15:689-96.

29. Nielsen MN, Sørensen J. Chitinolytic activity of Pseudomonas fluorescens isolates from barley and sugar beet rhizosphere. FEMS Microbiol Ecol. 1999; 30:217-27.

30. Gupta R, Saxena RK, Chaturvedi P, Virdi JS. Chitinase production by Streptomyces viridificans: Its potential in fungal cell wall lysis. J Appl Bacteriol. 1995;78:378-83.

31. Takayanagi $\mathrm{T}$, Ajisaki $\mathrm{K}$, Takiguchi $\mathrm{Y}$, Shimahara K. Isolation and characterization of thermostable chitinases from Bacillus licheniformis $\mathrm{X}-7 \mathrm{u}$. Biochimica et Biophysica Acta. 1991; 1078:404-10.

32. Arora N, Ahmad T, Rajagopal R, Bhatnagar RK. A constitutively expressed $36 \mathrm{kDa}$ exochitinase from Bacillus thuringiensis HD-1. Biochem Biophys Res Commun. 2003;307(3):620-25.

33. Mehmood MA, Latif M, Hafeez FY. Heterologous expression and characterization of an antifungal chitinase Chi39 from Bacillus thuringiensis serovar konkukian. Pak J Life Social Sci. 2012;10: 116-22.

34. Usharani TR, Gowda TKS. Cloning of chitinase gene from Bacillus thuringiensis. Indian J Biotechnol. 2011;10:264-269.

35. Roberts WK, Selitrennikoff CP. Plant and bacterial chitinases differ in antifungal activity. J Gen Microbiol. 1988;134:169-79.

(0) 2017 Daulagala; This is an Open Access article distributed under the terms of the Creative Commons Attribution License (http://creativecommons.org/licenses/by/4.0), which permits unrestricted use, distribution, and reproduction in any medium, provided the original work is properly cited.

Peer-review history:

The peer review history for this paper can be accessed here: http://sciencedomain.org/review-history/19226 